\title{
Cultural competencies and tips to keep in mind when in- teracting with Muslim patients
}

\author{
Farina Rafiq $q^{2,4}$, Ameer Jarrar ${ }^{2,4}$, Hayam Hamodat ${ }^{2,4}$, Malik Ali ${ }^{2,4}$, Saif Syed ${ }^{1,4}$, Babar \\ Haroon, $\mathrm{MD}^{3,4}$ \\ I. Class of 2019, Faculty of Medicine, Dalhousie University, Halifax, Nova Scotia, Canada. \\ 2. Class of 2020, Faculty of Medicine, Dalhousie University, Halifax, Nova Scotia, Canada. \\ 3. Department of Critical Care, Division of General Internal Medicine, Dalhousie University, Halifax, Nova Scotia, Canada \\ 4. Muslim Medical Association of Canada - Dalhousie Chapter.
}

U uslims make up a significant portion of the world 1 population, with an estimate of 1.8 billion people as of 2015. ${ }^{1}$ According to the 2011 Canadian census, Muslims make up 3.2\% of the Canadian population. ${ }^{2}$ As future physicians, many of us will encounter Muslims in our practice. Muslims come from different ethnicities and speak different languages. It is, therefore, essential to be conscious of core cultural values and practices commonly held by Muslims. This article will highlight cultural competencies and tips to keep in mind when interacting with Muslim patients.

\section{What is Islam?}

To better understand your Muslim patients' needs, consider the following concepts:

- The word "Islam" comes from the word, 'salam', meaning 'peace'.

- Muslims believe in one God and that the Prophet Muhammed is his final messenger.

- The Quran is the Holy Book and contains the teachings and values of the Islamic faith.

- Muslims pray five times a day (dawn, mid-day, late afternoon, sunset, and late evening).

- Muslims fast for 30 days during the month of Ramadan. Ramadan does not fall during a set month of the year as it follows the lunar calendar. During this month, Muslims abstain from food and drink from dawn to sunset.

- Hajj is the Holy pilgrimage to Mecca. Muslims are expected to make this pilgrimage at least once in their lifetime if they have the health and financial means to do so.

- The use of mind altering substances (alcohol, recreational drugs, etc.) and consumption of pork are prohibited.

\section{Things to Keep in Mind}

\section{Though people may identify as Muslim, not everyone practices the same.}

In Islam, as with any religion, people make their own personal decisions with regards to religious practices. For example, the Islamic faith prohibits the consumption of alcohol. However, that does not mean that you should not ask your Muslim patients about alcohol use. Similarly, some Muslim women wear the hijab (a head covering) while others choose not to.

\section{Be aware of the month of Ramadan when managing} patients and prescribing medications.

Ramadan is a month of fasting and a time of peace, family, charity, and worship. Muslims abstain from all food and drink (including water and medications!) from dawn to sunset. Fasting is not mandatory for the ill, the elderly/frail, those traveling, women during their menses, those who are pregnant or breastfeeding, and children before the age of 13 .

However, some patients may still choose to fast during Ramadan, despite it not being mandatory. Therefore, make sure to ask about medication compliance, look for signs of dehydration, and assess the overall health status of your patients who are choosing to fast. The dosing schedule of some medications can also be changed to accommodate for fasting (e.g. patients can take medications before dawn and after sunset). Please refer to the article "Managing medications during Ramadan fasting" for more information. ${ }^{3}$

\section{Be mindful of your interactions with Muslim patients of the opposite sex.}

Some Muslim patients may prefer to be examined by a healthcare professional of the same sex. They may also prefer having the curtain drawn or the door closed during a medical procedure. For example, a woman who prefers to be fully covered may not feel comfortable having her blood drawn in a setting where others can pass by. Additionally, do not be offended if you are not allowed to attend a Muslim woman's delivery!

However, do not let concerns of being of the opposite sex interfere with provision of urgent care for your patients; like in any situation, explain what you are doing and why, and proceed.

\section{Do not be afraid of examining a woman wearing a hijab (head-scarf).}

Though not all Muslim women wear the hijab, some women do, and it is important to be respectful of this when performing a physical exam. For example, if examining her scalp, ears, or neck, draw a curtain around the patient and only expose the necessary areas. Do not skip out on portions of the physical exam because of the hijab (you cannot comment on what you did not see!). Always ask for consent before you approach any patient. 
5. You can play a role in accommodating for Muslim patients choosing to pray.

Muslims pray five times a day and patients you encounter may request a place to pray. It may be helpful to know where a quiet space or a chapel is located in your healthcare setting. Just to note, Islamic prayer is brief (usually less than five minutes).

\section{Arrange for interpretation services when needed.}

With the recent influx of many refugees and immigrants who cannot communicate in English, it is imperative that we, as healthcare providers, facilitate communication via translation and interpretation services. If the service of local professional interpreters cannot be obtained in your institution, you can always use the Language Line: 1 (800) 752-6096. Please do not seek the help of patient family members or non-professionally trained interpreters.

\section{Be aware that some Muslims do not consume pork or pork-containing products.}

Some medications are delivered in capsules made of pork-derived gelatin. If you are prescribing a medication with a capsule, tell your patient to ask their pharmacist regarding the capsule derivative. Your patients can then decide whether they want to take this medication. You may also consider pork-free alternatives. Additionally, some hospital foods may contain pork and it is courteous to mention this to your patients and offer other options. You can learn more about pork-based products in medications here. ${ }^{4}$

We hope that you find these points helpful and that you integrate them into your practice. As always, please note that these are general guidelines and that people make individual choices in religious practices and lifestyles. Always ask your patients without making assumptions.

If you have further questions about Islam or cultural competency, please feel free to initiate conversations with your Muslim colleagues, and do not hesitate to reach out to any of these local Islamic centres:

- Ummah Masjid and Community Centre (Halifax): management@umcc.ca

- Centre of Islamic Development (Halifax): cidonline. halifax@gmail.com

- Muslim Association of New Brunswick (Saint John): info@manb.ca

- Masjid Dar As-Salam (Prince Edward Island): (902) 367-3659

\section{References}

1. Lipka. M, Hackett. C. (2017). Why Muslims are the world's fastest-growing religious group.

2. Statistics Canada. (2011). National Household Survey. Rerieved from https://www12.statcan.gc.ca/nhs-enm/2011/dp-pd/ prof $/$ details $/$ page.cfm? Lang =E\&Geo1 = PR\&Code1 =01\&Data $=$ Count $\&$ SearchText $=$ Canada $\&$ Search Type $=$ Begins $\&-$ SearchPR=01\&A1=Religion $\& B 1=$ All $\&$ Custom $=\& T A B I D=1$

3. Grdindrod. K, and Alsabbagh. W. (2017). Managing medications during Ramadan fasting. Can Pharm J (Ott). 150(3): 146-149.

4. Medicines/pharmaceuticals of animal origin. (2013). Retrieved from https://www.health.qld.gov.au/_data/assets/pdf file/0024/147507/qh-gdl-954.pdf

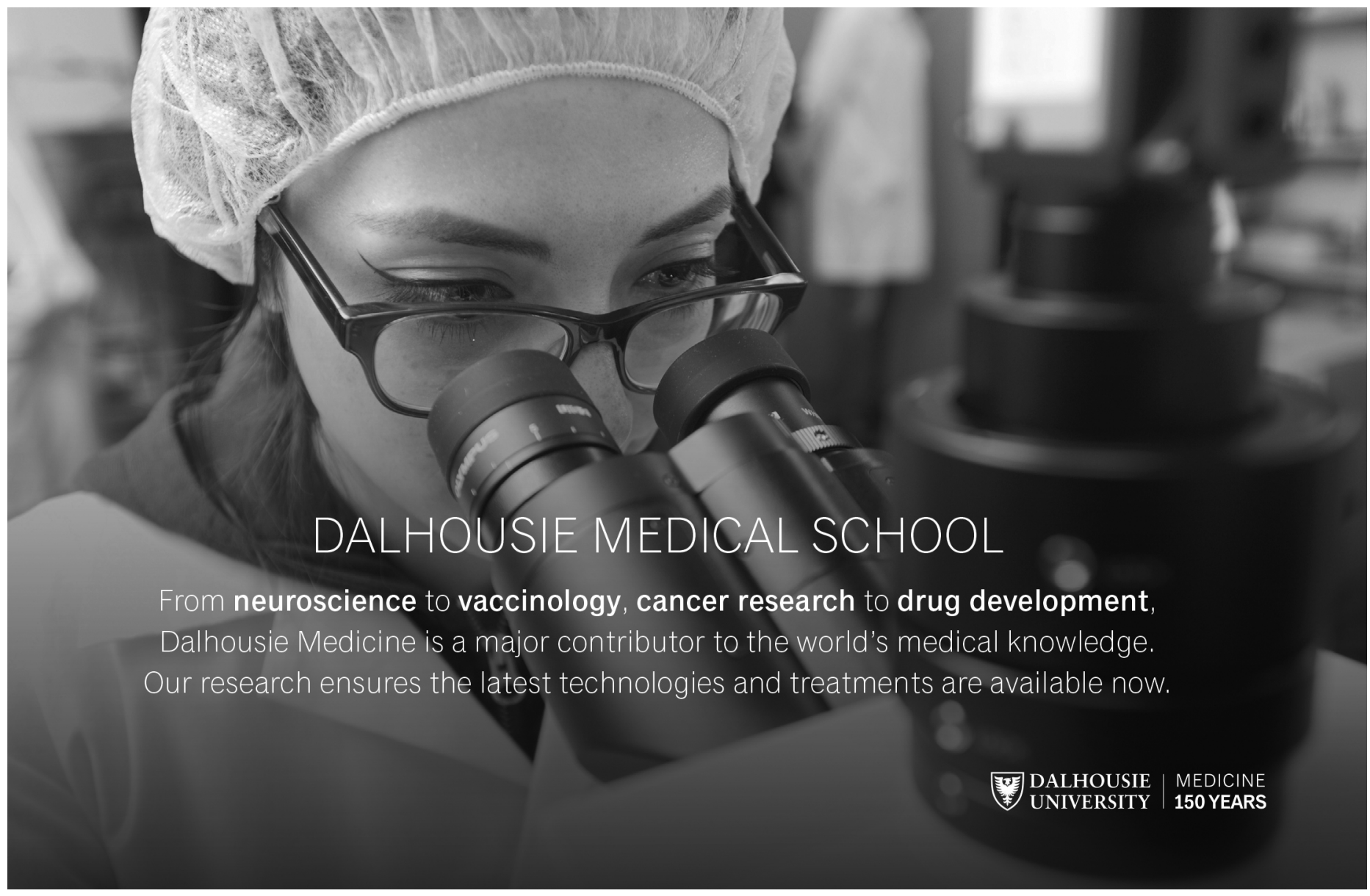

